\title{
Pulse-synchronous pendular nystagmus following cholesteatoma surgery
}

自

\section{Figure $\quad$ CT scan of the perilymph fistula}

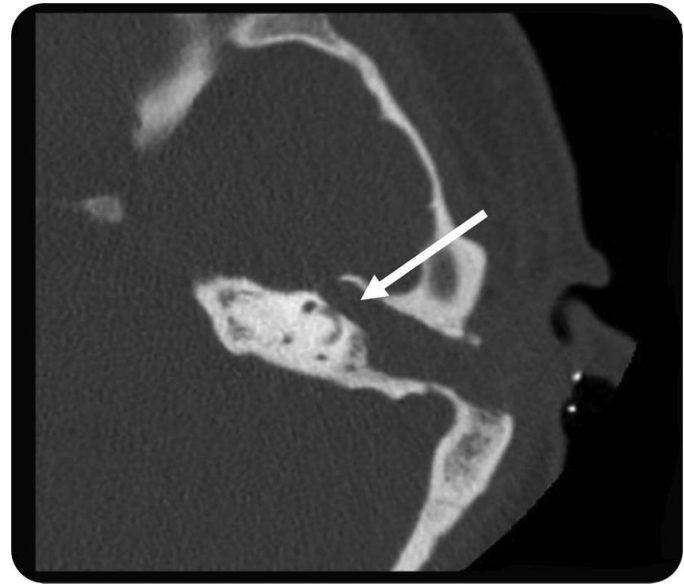

Cranial CT scan shows the left temporal bone at the level of the horizontal semicircular canal after cholesteatoma removal. Arrow points to perilymph fistula.

A 33-year-old woman developed nausea, vertigo, and oscillopsia immediately after surgery for a left ear cholesteatoma. Vertigo increased during Valsalva maneuver. Neurologic examination showed a pulsesynchronous pendular nystagmus (video on the Neurology ${ }^{\circledR}$ Web site at Neurology.org) and postural imbalance. Cerebral MRI was inconspicuous. CT disclosed a discontinuity of the temporal bone lateral to the left horizontal semicircular canal, compatible with perilymph fistula (figure). After revision surgery, the symptoms disappeared. Acquired pendular nystagmus is a neuro-ophthalmologic finding that is almost exclusively caused by CNS disorders. ${ }^{1}$ However, occurrence with postsurgical perilymph fistula has been reported. ${ }^{2}$ Pulsesynchronicity of ocular oscillations may help to identify peripheral causes.

Kaspar-Josche Streitberger, MD, Martin Khan, MD, Christoph J. Ploner, MD

From Charité-Universitätsmedizin Berlin, Germany.

Author contributions: Dr. Streitberger was responsible for the following points: study concept and design, acquisition of data, analysis and interpretation, critical revision of the manuscript for important intellectual content. Dr. Khan was responsible for the following points: acquisition of data, critical revision of the manuscript for important intellectual content. Prof. Ploner was responsible for the following points: study concept and design, acquisition of data, analysis and interpretation, critical revision of the manuscript for important intellectual content, study supervision.

Study funding: No targeted funding reported.

Disclosure: The authors report no disclosures relevant to the manuscript. Go to Neurology.org for full disclosures.

Correspondence to Dr. Ploner: christoph.ploner@charite.de

Supplemental data at Neurology.org
1. Leigh R, Zee D. The Neurology of Eye Movements. New York: Oxford University Press; 2006.

2. Rambold H, Heide W, Sprenger A, et al. Perilymph fistula associated with pulse-synchronous eye oscillations. Neurology 2001; 65:1769-1771. 